\title{
Optimal Capacity and Location Wind Turbine to Minimize Power Losses Using NSGA-II
}

\author{
Dieta Wahyu Asry Ningtias ${ }^{1}$, Fransisco Danang Wijaya ${ }^{2}$, Lesnanto Multa Putranto ${ }^{3}$
}

\begin{abstract}
Voltage deviations and power losses in the distribution network can be handled in various ways, such as adding diesel power plants and wind turbines. Adaut Village, Tanimbar Islands Regency, Maluku Province has installed a diesel power plant with a capacity of $1,200 \mathrm{~kW}$, while the average hourly electricity load is $374.9 \mathrm{~kW}$. Adaut Village has high wind potential that can be used for distributed generations namely wind turbine (WT). WT can be used to improve power quality in terms of power losses and voltage deviations. In adding WT, the capacity and location must be determined to get good power quality in terms of power loss and voltage deviation. The research applied an optimization technique for determining the capacity and location of WT using non-dominated sorting genetic algorithm II (NSGAII) with an objective function of power losses and voltage deviation. In addition, the economic aspects of the power plant were calculated using the levelized cost of energy (LCOE). The research used scenarios based on the number of WT installed. The best results were obtained in scenario IV or 4 WT with $1.38 \mathrm{~kW}$ on Bus 2, $422.43 \mathrm{~kW}$ on Bus 15, 834.33 kW on Bus 30, and 380.81 $\mathrm{kW}$ on Bus 31 which could reduce power losses by $80 \%$ with an LCOE value of $R p 7,113.15 / \mathrm{kWh}$. The addition of the WT could also increase the voltage profile to close to $1 \mathrm{pu}$, which means it can minimize the voltage deviation in the distribution network.
\end{abstract}

Keywords - Wind Turbine, Non-Dominated Genetic Algorithm II, Power Loss, Voltage Deviation, Levelized Cost of Energy.

\section{INTRODUCTION}

The distribution network is part of the electric power system that distributes electrical energy from large power sources to loads or consumers. These consumers are, for example industries, factories, and households both in urban areas and in the outermost islands [1]. The distribution network has an inductive load that can cause voltage deviation and power losses. Voltage deviation is indicated by the voltage value below or above of nominal voltage value at each bus in the network system. While power losses are the loss of power in the process of sending electrical power from the source to the load [2]. The large voltage deviation and power losses can cause a decrease in power quality. It can be detrimental to both consumers and electricity producers. The loss from the consumer side is poor voltage quality caused by excess or lack of the nominal value or standard, while the loss from the producer side is voltage deviation and power losses which can cause wasted power leading to revenue reduction [3].

Voltage deviation and power losses in the distribution network can be handled in various ways such as adding distributed generation (DG) [4], [5]. DG is a small-scale power plant installed in the distribution network [6]. Power plant includes electric steam power plant, hydroelectric power plant,

1,2,3 Department of Electrical and Information Engineering, Faculty of Engineering, Universitas Gadjah Mada, Jln. Grafika No.2, Kampus UGM, Yogyakarta, 55281, INDONESIA (phone: 0274552305; e-mail: $\quad{ }^{1}$ dieta.w.a@mail.ugm.ac.id, ${ }^{2}$ danangwijaya@ugm.ac.id, ${ }^{3}$ lesnanto@ugm.ac.id) gas power plant, diesel power plant, wind power plant, and nuclear power plant. The selection of the power plant is based on the location, purpose of generation, and potential of an area [1]. Diesel power plant can be added to the distribution network due to its fast response to load [7]. Adaut Village, Tanimbar Islands District, Maluku Province has a diesel power plant with a capacity of $1,200 \mathrm{~kW}$, while the average hourly electricity load is $374.9 \mathrm{~kW}$ accumulated based on one-year data. In addition, Adaut Village has high wind potential that can be used for distributed generations namely wind turbine (WT). WT can be used to improve power quality in terms of power losses and voltage deviations.

In adding WT, the capacity and location must be determined to get good power quality in terms of power loss and voltage deviation. There are several studies on methods to determine the capacity and location of a power plant, namely analytic, classical (non-heuristic), meta-heuristic optimization, and mixed methods. The analytical method is more suitable for small and simple networks, and less suitable for large and complex networks. Then, the analytical method also does not work well if the load varies, it is more suitable to use if the load state has the same value [8]. The classical method can provide a solution even though the computational load is high. Sometimes, the solutions given are not decent because there is a convergence problem. The meta-heuristic optimization method is more suitable and works better in terms of convergence and accuracy when used on large and complex networks. The meta-heuristic optimization method can increase power quality and reduce power losses [9], [10].

The meta-heuristic optimization methods include genetic algorithm (GA), tabu search (TS), bat algorithm (BA), shuffled frog leaping algorithm (SFLA), artificial bee colony (ABC), particle swarm optimization (PSO), cuckoo search, bacterial foraging optimization, ant colony optimization, flower pollination algorithm, firefly algorithm, ant-lion optimization, oppositional krill herd optimization, intelligent water drop, and invasive weed optimization.

This research used multiple objectives, namely minimizing power losses and voltage deviations, so the authors used the non-dominated sorting genetic algorithm II (NSGA-II) based on GA model to obtain more optimal results. It was selected because it is simpler, does not require complex mathematical formulations, works well under varying load conditions, and reduces power losses [8], [11]. The test system used was the IEEE 33 bus radial distribution network with a case study of Adaut Village, Tanimbar Islands District, Maluku Province. In addition, the research also planned cost aspects. Cost calculation used levelized cost of energy (LCOE). There are other studies using LCOE in calculating the cost of WT. The study with a 2 MW WT capacity was conducted in the Catanduva region, São Paulo City, Brazil, with an LCOE value of US\$46.71/MW. While in the Birigui region, São Paulo City, Brazil, the LCOE value was US\$55.26/MW [9]. 
The structure of this paper is organized as follows. Section II discusses the proposed method. Section III shows the simulation setup. Section IV discusses and analyses the simulation results. Section V describes the conclusion.

\section{Proposed Method}

The aim of the research is to reduce power loss and voltage deviations in the distribution network by installing WT and diesels. However, the size of the capacity and the installation location must be considered. In this research, the location and capacity of WT and diesel were optimized using NSGA-II. At the end of the research, the generation cost was calculated using the LCOE method.

\section{A. Objective Function}

This research determined the capacity and location with the aim of reducing power losses and voltage deviations in the distribution network, therefore the objective function is formulated as follows:

$$
O F=\min \sum_{t=1}^{T}\left(P_{t L o s s}+V_{t D i}\right)
$$

with $P_{t L o s s}$ is the active power losses at time $t$ and $V_{t D i}$ is the deviation of voltage at time $t . T$ is the total time and $t$ is the index of time. The total active power losses in the distribution network can be calculated using an equation known as the "exact loss formula" written in (2).

1) Power Loss: The following is the formula used to calculate the power loss.

$$
\begin{aligned}
& P_{\text {tLoss }}=\sum_{i=1}^{N} \sum_{j=1}^{N}\left[\alpha_{i j}\left(P_{t i} P_{t j}+Q_{t i} Q_{t j}\right)\right. \\
& \left.+\beta_{i j}\left(Q_{t i} P_{t j}-P_{t i} Q_{t j}\right)\right] \\
& \alpha_{i j}=\frac{r_{i j}}{V_{i} V_{j}} \cos \left(\delta_{i}-\delta_{j}\right) \\
& \beta_{i j}=\frac{r_{i j}}{V_{i} V_{j}} \sin \left(\delta_{i}-\delta_{j}\right)
\end{aligned}
$$

with $\alpha_{i j}$ and $\beta_{i j}$ are coefficient of magnitude and phase voltage, respectively. $P_{t i}$ dan $P_{t j}$ are injection of active power on bus $i$ and bus $j$ when time $t . Q_{t i}$ dan $Q_{t j}$ are injection of reactive power on bus $i$ and bus $j$ when time $t . N$ is number of buses. $V_{i}<\delta_{i}$ is complex voltage of bus $i$. Then the $r_{i j}+j x_{i j}=Z_{i j}$ is the element $i-j$ of impedance matrix ( $Z$ bus).

If a WT was added to the distribution network, the power injection at bus $i$ is as follows:

$$
P_{i}=P_{D i}+P_{L i}-P_{W T i}
$$

with $P_{L i}$ was ignored, then:

$$
P_{i}=P_{D i}-P_{W T i}
$$

$P_{i}$ is the power injection in line $i . P_{D i}$ is the power demand in line $i . P_{L i}$ is the power loss in line $i . P_{W T i}$ is the power injection of WT in line $i$.

2) Voltage Deviation: The research observed the effect when a WT was added in terms of voltage changes on the network bus obtained through the following equation:

$$
V_{t D i}=\sum_{i=1}^{N}\left|1-V_{t i}\right|
$$

where $V_{t D i}$ is the change in the initial voltage value or the difference between the initial voltage $(1 \mathrm{pu})$ and the actual voltage on bus $i$ when time $t$. $V_{t i}$ is the voltage on bus $i$ when time $t$. The value of 1 indicates $1 \mathrm{pu}$, while $N$ denotes the number of buses.

\section{B. Constraint}

1) Voltage: In this research, the simulation was given restraints so that the voltage from the optimization results was in the range of standard stress limits. Based on the regulation of the Minister of Energy and Mineral Resources of the Republic of Indonesia Number 20 of 2020 concerning the Regulation of the Electric Power System Network (Grid Code), the voltage standard is within the limits of $+5 \%$ and $-10 \%$, so that the voltage constraints of this study are as follows:

$$
\begin{gathered}
V_{t i} \min <V_{t i}<V_{t i} \max \\
0.95 \mathrm{pu}<V_{t i}<1.05 \mathrm{pu}
\end{gathered}
$$

with $V_{t i}$ is the voltage on bus $i$ when time $t$.

2) Capacity of Wind Turbine: The research carried out optimization to get the minimal power losses and voltage deviation by applying the optimal value of the WT capacity. The value of the WT capacity also considers the magnitude of the load value. Here is the equation of the capacity constraint:

$$
\begin{gathered}
P_{\min }<P_{i}^{\text {capacity }}<P_{\max } \\
0 \mathrm{MW}<P_{i}^{\text {capacity }}<4 \mathrm{MW}
\end{gathered}
$$

with $P_{i}^{\text {capacity }}$ is the active power capacity of the installed WT.

\section{Load Flow Calculation}

Load flow is carried out to calculate the four variables associated with nodes, namely bus voltage magnitude $(V)$, voltage angle $(\delta)$, real power $(P)$, and reactive power $(Q)$ [10], [11]. In this research, load flow was calculated by Newton Raphson. The calculation began by forming an impedance matrix with the following formula:

$$
Z_{i j}=R_{i j}+j X_{i j}
$$

with $Z_{i j}, R_{i j}$, and $j X_{i j}$ are the impedance, resistance, and reactance between bus $i$ and bus $j$. After that, the network impedance was converted to admittance matrix:

$$
Y_{i j}=Y r_{i j}+J Y x_{i j}
$$

with

$$
\begin{gathered}
Y r_{i j}=\frac{R_{i j}}{R_{i j}^{2}+X_{i j}^{2}} \\
Y x_{i j}=\frac{X_{i j}}{R_{i j}^{2}+X_{i j}^{2}} .
\end{gathered}
$$

Subsequentlly, the $Y$ bus admittance matrix was formed with components consisting of network admittance, line capacitance, and transformer tapping change. The $Y$ bus admittance matrix 
formed in rectangular form was converted into polar form, where, previously, the $Y$ bus admittance matrix was separated into components of the $G$ matrix and the $B$ matrix. The scheduled power on each bus could be calculated using (15) and (16).

$$
\begin{gathered}
P_{i}^{j d}=P_{G i}-P_{L i} \\
Q_{i}^{j d}=Q_{G i}-Q_{L i}
\end{gathered}
$$

with $P_{i}^{j d}$ and $Q_{i}^{j d}$ are the active and reactive scheduled power, respectively. $P_{G i}$ and $Q_{G i}$ are the active and reactive power generation. $P_{L i}$ and $Q_{L i}$ are active and reactive power demand. Iteration process by Newton Raphson was looking for calculated power using (17) and (18).

$$
\begin{gathered}
P_{i}=\sum_{n=1}^{N}\left|Y_{i n} V_{i} V_{n}\right| \cos \left(\theta_{i n}+\delta_{n}-\delta_{i}\right) \\
Q_{i}=-\sum_{n=1}^{N}\left|Y_{i n} V_{i} V_{n}\right| \sin \left(\theta_{i n}+\delta_{n}-\delta_{i}\right)
\end{gathered}
$$

with $P_{i}$ and $Q_{i}$ are the active and reactive power calculated. $V_{i}$ and $\theta_{i}$ are the voltage magnitude and phase angle on bus $i$, meanwhile $V_{j}$ and $\theta_{j}$ are the magnitude and phase angle on bus $j$. $Y_{\text {in }}$ and $\theta_{\text {in }}$ are the magnitude and phase angle of admittance matrix element $Y$. Then, the power mismatch, which was the difference between the scheduled power and the calculated power, could be obtained using the following equations:

$$
\begin{aligned}
& \Delta P_{i}=P_{i}^{j d}-P_{i}^{h i t} \\
& \Delta Q_{i}=Q_{i}^{j d}-Q_{i}^{h i t}
\end{aligned}
$$

with $\Delta P_{i}$ and $\Delta Q_{i}$ are the active and reactive power mismatch on bus $i$. After the power mismatch value was obtained, then a Jacobian matrix was formed, as shown in (21).

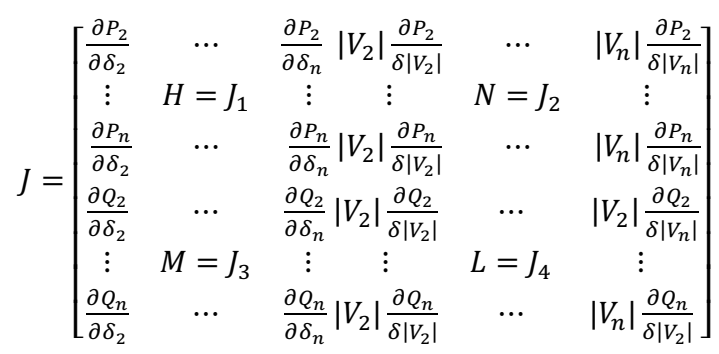

The Jacobian matrix consists of four submatrixes, namely the $H, N, M$, and $L$ submatrixes which can be expressed by other names, namely $J_{1}, J_{2}, J_{3}$, and $J_{4}$. The submatrix $J_{1}$ or $H$ can be calculated by the following equation: calculation for off diagonal component and diagonal component in (22) and (23).

$$
\begin{gathered}
\frac{\partial P_{i}}{\partial \delta_{j}}=-\left|V_{i} V_{j} Y_{i j}\right| \sin \left(\theta_{i j}+\delta_{j}-\delta_{i}\right) \\
\frac{\partial P_{i}}{\partial \delta_{j}}=\sum_{n=1, n \neq i}^{N}\left|V_{i} V_{n} Y_{i n}\right| \sin \left(\theta_{i n}+\delta_{n}-\delta_{i}\right) .
\end{gathered}
$$

Then, the diagonal component was compared with $Q_{i}^{\text {hit }}$ so that it obtained the following equation.

$$
\frac{\partial P_{i}}{\partial \delta_{j}}=-Q_{i}-\left|V_{i}\right|^{2} B_{i i}
$$

The submatrix $J_{3}$ or $M$ can be calculated by the following equation: calculation for off diagonal component and diagonal component in (25) and (26).

$$
\begin{gathered}
\frac{\partial Q_{i}}{\partial \delta_{j}}=-\left|V_{i} V_{j} Y_{i j}\right| \cos \left(\theta_{i j}+\delta_{j}-\delta_{i}\right) \\
\frac{\partial Q_{i}}{\partial \delta_{i}}=\sum_{n=1, n \neq i}^{N}\left|V_{i} V_{j} Y_{i j}\right| \cos \left(\theta_{i j}+\delta_{j}-\delta_{i}\right)=\sum_{n=1, n \neq i}^{N} \frac{\partial Q_{i}}{\partial \delta_{n}} .
\end{gathered}
$$

The diagonal component of $J_{3}$ or $M$ was then compared with $P_{i}^{\text {hit }}$ so that it obtained (27).

$$
\frac{\partial Q_{i}}{\partial \delta_{i}}=P_{i}-\left|V_{i}\right|^{2} G_{i i}
$$

The submatrix $J_{2}$ or $N$ can be calculated by the following equation: calculation for off diagonal component and diagonal component in (28) and (29).

$$
\begin{aligned}
& \left|V_{j}\right| \frac{\partial P_{i}}{\partial\left|V_{j}\right|}=\left|V_{j}\right|\left|V_{I} V_{i j}\right| \cos \left(\theta_{i j}+\delta_{j}-\delta_{i}\right) \\
& \left|V_{i}\right| \frac{\partial P_{i}}{\partial\left|V_{i}\right|}=\frac{\partial Q_{i}}{\partial \delta_{i}}+2\left|V_{i}\right|^{2} G_{i i}=P_{i}+\left|V_{i}\right|^{2} G_{i i} .
\end{aligned}
$$

The submatrix $J_{4}$ or $L$ can be calculated by the following equation: calculation for off diagonal component and diagonal component in (30) and (31).

$$
\begin{gathered}
\left|V_{j}\right| \frac{\partial Q_{i}}{\partial\left|V_{j}\right|}=-\left|V_{j}\right|\left|V_{i} Y_{i j}\right| \sin \left(\theta_{i j}+\delta_{j}-\delta_{i}\right)=\frac{\partial P_{i}}{\partial \delta_{j}} \\
\left|V_{i}\right| \frac{\partial Q_{i}}{\partial\left|V_{i}\right|}=-\frac{\partial P_{i}}{\partial \delta_{i}}-2\left|V_{i}\right|^{2} B_{i i}=Q_{i}-\left|V_{i}\right|^{2} B_{i i}
\end{gathered}
$$

with $\frac{\partial P_{i}}{\partial \delta_{i}}$ and $\frac{\partial P_{i}}{\partial \delta_{j}}$ are the elements of the $J_{1}$ submatrix or $H \cdot \frac{\partial P_{i}}{\partial \delta_{j}}$ and $\frac{\partial Q_{i}}{\partial \delta_{i}}$ are the elements of the $J_{3}$ submatrix or $M .\left|V_{j}\right| \frac{\partial P_{i}}{\delta\left|V_{j}\right|}$ and $\left|V_{i}\right| \frac{\partial P_{i}}{\delta\left|V_{i}\right|}$ are the elements of the $J_{2}$ submatrix or $N .\left|V_{j}\right| \frac{\partial Q_{i}}{\delta\left|V_{j}\right|}$ and $\left|V_{i}\right| \frac{\partial Q_{i}}{\delta\left|V_{i}\right|}$ are the elements of the $J_{4}$ submatrix or $L . V_{i}$ and $\theta_{i}$ are the voltage magnitude and phase angle on the bus $i . V_{j}$ and $\theta_{j}$ are the voltage magnitude and phase angle on the bus $j . P_{i}$ and $Q_{i}$ are active and reactive power on the bus $i$. $Y_{\text {in }}$ and $\theta_{i n}$ are the magnitude and phase angle admittance on the bus $i$ to $n$. $G_{i i}$ and $B_{i i}$ are the conductance and susceptance on the bus $i$.

After obtaining the results of the calculation of each element in the Jacobian submatrix, then the Jacobian matrix was formed by combining four Jacobian submatrixes so that the power flow equation was formed, as in (32).

$$
\left[\begin{array}{c}
\Delta P \\
\Delta Q
\end{array}\right]=\left[\begin{array}{cc}
H & N \\
J & L
\end{array}\right]\left[\begin{array}{c}
\Delta \delta \\
\frac{\Delta|V|}{|V|}
\end{array}\right]=\left[\begin{array}{ll}
J_{1} & J_{2} \\
J_{3} & J_{4}
\end{array}\right]\left[\begin{array}{c}
\Delta \delta \\
\frac{\Delta|V|}{|V|}
\end{array}\right]
$$

The Jacobian matrix formed was then inverted. Next, the phase angle and voltage magnitude values on each bus were recalculated or updated using the following equation:

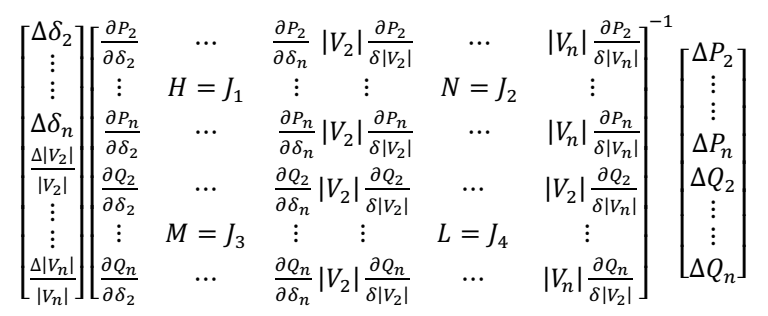

The results of the multiplication were then separated and the change in the phase angle of the voltage and the bus voltage $i$ could be calculated as in (34) and (35). 


$$
\begin{gathered}
\Delta \delta_{i}^{(k+1)}=\delta_{i}^{(k)}+\Delta \delta_{i}^{k} \\
\left|V_{i}\right|^{(k+1)}=\left|V_{i}\right|^{(k)}+\Delta\left|V_{i}\right|^{(k)} \\
=\left|V_{i}\right|^{(k)}\left(1+\frac{\Delta\left|V_{i}\right|^{(k)}}{\left|V_{i}\right|^{(k)}}\right)
\end{gathered}
$$

with $\partial \delta_{i}$ is the change in phase angle voltage on the bus $i$ and $\Delta\left|V_{i}\right|$ is the change in voltage magnitude or voltage deviation on the bus $i$.

The difference or change in the value of the phase angle and the magnitude of the voltage between the old and the new was then compared with the predetermined accuracy value. If the accuracy value had not been reached, then it was continuously iterated until the accuracy value was obtained and converged. After convergence was obtained, the power on the slack bus was calculated using the following equation:

$$
\begin{gathered}
P_{i}=\sum_{n=1}^{N}\left|Y_{i n} V_{i} V_{n}\right| \cos \left(\theta_{i n}+\delta_{n}-\delta_{i}\right) \\
Q_{i}=\sum_{n=1}^{N}\left|Y_{i n} V_{i} V_{n}\right| \sin \left(\theta_{i n}+\delta_{n}-\delta_{i}\right)
\end{gathered}
$$

with $P_{i}$ and $Q_{i}$ are the active and reactive power on the slack bus. Then, the power flow between buses could be calculated using the following equation:

$$
\begin{gathered}
S_{i j}=V_{i}\left(V_{i j}^{*} Y_{i j}^{*}+V_{i}^{*} Y_{c_{i j}}^{*}\right) \\
P_{i j}-J Q_{i j}=V_{i}^{*}\left(V_{i}-V_{j}\right) Y_{i j}+V_{i}^{*} V_{i} Y c_{i j}
\end{gathered}
$$

with $S_{i j}, P_{i j}, Q_{i j}$ are the complex, active, and reactive power flow from bus $i$ to bus $j . V_{i}$ and $V_{j}$ are the voltage vector on the bus $i$ and $j . V_{i j}, Y_{i j}$, and $Y c_{i j}$ are the voltage vector, admittance, and admittance line charging between bus $i$ and bus $j$.

Calculation of power flow could determine the value of the power losses on the network. Power losses between buses could be calculated using the following equation:

$$
S_{i j}(\text { losses })=S_{i j}+S_{j i}
$$

with $S_{i j}$ (losses) is the complex power losses from bus $i$ to bus $j$. $S_{i j}$ is the complex power from bus $i$ to bus $j$. Meanwhile, $S_{j i}$ is the complex power from bus $j$ to bus $i$.

\section{Non-Dominated Sorting Genetic Algorithm II}

NSGA-II is a method used to solve a value search in an optimization problem. This method was developed based on a GA that uses the principles of genetics and the natural selection process of Darwin's evolution theory. The development of generations in natural populations follows the principle of "only the strong survives" natural selection. The GA can be used to find solutions to real-world problems by imitating the theory of evolution [12].

In this research, the capacity and location of WT were determined with the aim of reducing power losses and voltage deviations using the NSGA-II based on the GA. The method was chosen as it is simpler, does not require complex mathematical formulations, works well under varying load conditions, and is able to reduce power losses [13], [14]. This research used a population value of 100 , iteration of 200 , crossover probability of 0.8 , and mutation probability of 0.3 .

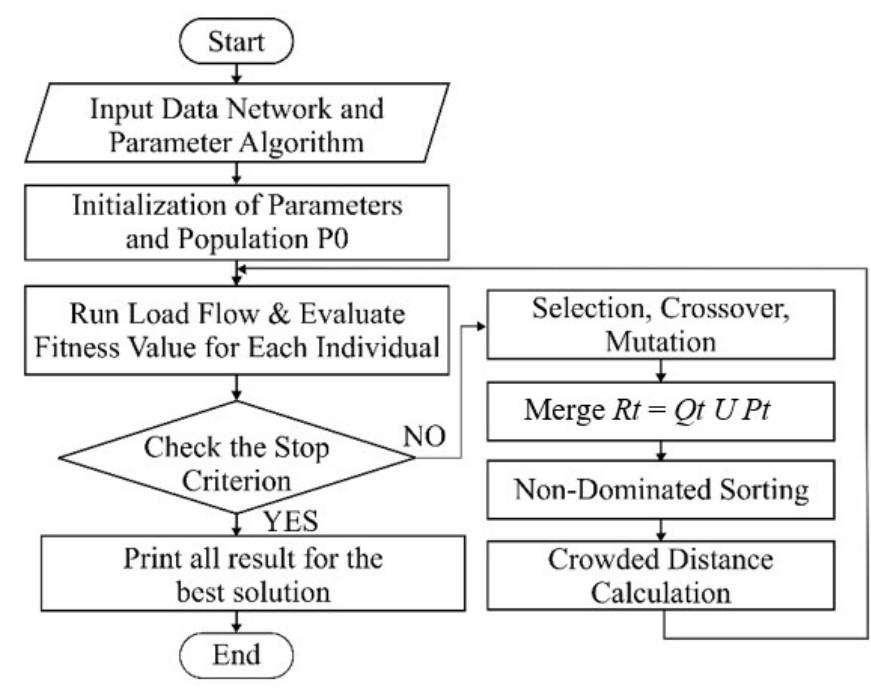

Fig. 1 Optimization method stages.

Based on Fig. 1, the process of the proposed method is as follows:

1. Input network data (line data, bus data, load, and wind speed) and algorithm parameters (population number, number of chromosomes or individuals, crossover, and mutation probabilities).

2. Initialization of parameter and population. Generate initial population $P_{0}$ or generation $t=0$.

$$
\begin{aligned}
& P_{0}=\left[\begin{array}{lll}
x_{1} & x_{2} & x_{N_{p o p}}
\end{array}\right] \\
& x_{i}=\left[\begin{array}{ll}
W T_{\text {loc }} & W T_{\text {size }}
\end{array}\right]
\end{aligned}
$$

with $x_{i}$ is an individual.

$W T_{\text {loc }}=$ [randsrc(1,no_of_wt,minval1:maxval1)]

$W T_{\text {size }}=[$ randsrc(1,no_of_wt,minval2:maxval2)]

with minvall and maxvall are bus 1 and bus 33, while minval2 and maxval2 are 0 and $4 \mathrm{MW}$. The randsrc means the random number is uniformly distributed.

3. The new individuals then form the parent population at time $t\left(P_{t}\right)$. Then, load flow for each individual is executed in $P_{t}$ with the Newton Raphson. The fitness value is then evaluated by (1).

4. Generating the first offspring population. After that, check the constraints of load flow analysis and max generation. If the constraints are met, proceed to the next step, otherwise add a penalty term to the objective function.

5. Generating first offspring $\left(Q_{t}\right)$ formed by selection, crossover, and mutation.

6. Combining the first offspring population $\left(Q_{t}\right)$ and the parent population $\left(P_{t}\right)$ into $R t$.

$$
R_{t}=Q_{t} \cup P_{t}
$$

7. On the Rt, non-dominated sorting is then carried out by sorting the minimum objective function (OF) results. The highest-ranking is with the largest minimum OF.

8. A new population of $P_{t+1}$ is formed in the $N_{p o p}$ population which is added from the ranking results. After that, a calculation based on the crowded distance 


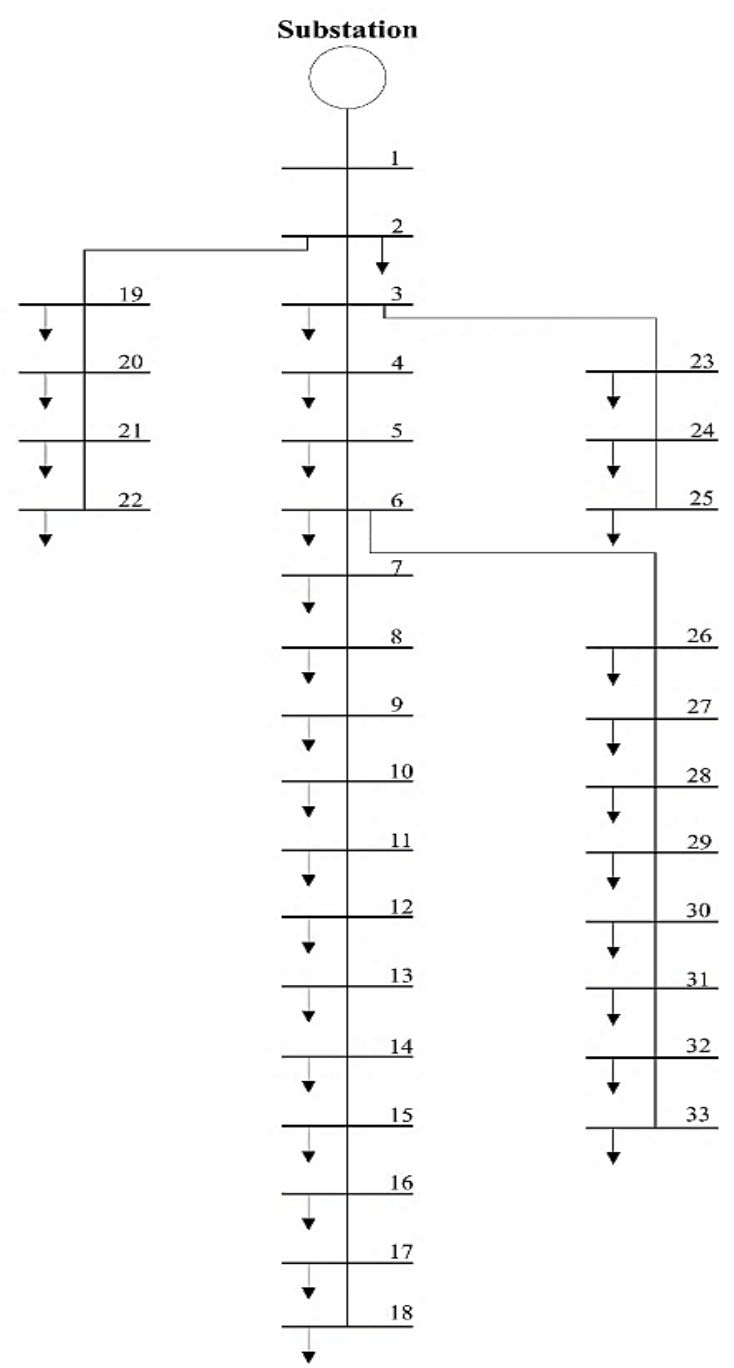

Fig. 2 IEEE 33 bus system.

is applied with a certain size limit. The greater the value of the crowded distance is better.

9. Looping or repetition of steps three to eight until it reaches the maximum population.

10. Getting the best results with the capacity and location of WT minimizing power losses and voltage deviations.

\section{E. Economic Aspect}

The economic aspect in this study was calculated to determine the recommended selling price of electricity when the minimum power losses and voltage deviations were reached. The cost of generating diesel and WT in the distribution network can be calculated using the LCOE. LCOE is the main cost of energy production so that the economic aspect of the distribution network can be analyzed. LCOE is the sum of investment costs, operation and maintenance costs, and fuel costs. The formula is shown in (44) obtained from (45)-(48).

$$
\begin{gathered}
\operatorname{LCOE}(\$ / \mathrm{MWh})=\frac{F P M \times \operatorname{Cost}}{\text { Avail } \times 8,760}+\frac{O M}{\text { Avail } \times 8,760}+\frac{0,860 \times B B B}{E f f}(44) \\
F P M=\frac{d \times(1+d)^{\text {Tekonom }}}{(1+d)^{\text {Tekonom }}-1}
\end{gathered}
$$

TABLE I

DATA BUS AND LINE DATA

\begin{tabular}{|c|c|c|c|c|c|c|}
\hline Bus & $\begin{array}{c}\boldsymbol{P} \\
(\mathbf{k W})\end{array}$ & $\begin{array}{c}\boldsymbol{Q} \\
\text { (kVar) }\end{array}$ & $\begin{array}{c}\text { From } \\
\text { Bus- }\end{array}$ & $\begin{array}{c}\text { To } \\
\text { Bus- }\end{array}$ & $\begin{array}{c}\boldsymbol{R} \\
(\mathbf{O h m})\end{array}$ & $\begin{array}{c}\boldsymbol{X} \\
\text { (Ohm) }\end{array}$ \\
\hline 1 & 0 & 0 & 1 & 2 & 0.0922 & 0.0470 \\
\hline 2 & 100 & 60 & 2 & 3 & 0.4930 & 0.2511 \\
\hline 3 & 90 & 40 & 3 & 4 & 0.3660 & 0.1864 \\
\hline 4 & 120 & 80 & 4 & 5 & 0.3811 & 0.1941 \\
\hline 5 & 60 & 30 & 5 & 6 & 0.8190 & 0.7070 \\
\hline 6 & 60 & 20 & 6 & 7 & 0.1872 & 0.6188 \\
\hline 7 & 200 & 100 & 7 & 8 & 0.7114 & 0.2351 \\
\hline 8 & 200 & 100 & 8 & 9 & 1.0300 & 0.7400 \\
\hline 9 & 60 & 20 & 9 & 10 & 1.0440 & 0.7400 \\
\hline 10 & 60 & 20 & 10 & 11 & 0.1966 & 0.0650 \\
\hline 11 & 45 & 30 & 11 & 12 & 0.3744 & 0.1238 \\
\hline 12 & 60 & 35 & 12 & 13 & 1.4680 & 1.1550 \\
\hline 13 & 60 & 35 & 13 & 14 & 0.5416 & 0.7129 \\
\hline 14 & 120 & 80 & 14 & 15 & 0.5910 & 0.5260 \\
\hline 15 & 60 & 10 & 15 & 16 & 0.7463 & 0.5450 \\
\hline 16 & 60 & 20 & 16 & 17 & 1.2890 & 1.7210 \\
\hline 17 & 60 & 20 & 17 & 18 & 0.7320 & 0.5740 \\
\hline 18 & 90 & 40 & 2 & 19 & 0.1640 & 0.1565 \\
\hline 19 & 90 & 40 & 19 & 20 & 1.5042 & 1.3554 \\
\hline 20 & 90 & 40 & 20 & 21 & 0.4095 & 0.4784 \\
\hline 21 & 90 & 40 & 21 & 22 & 0.7089 & 0.9373 \\
\hline 22 & 90 & 40 & 3 & 23 & 0.4512 & 0.3083 \\
\hline 23 & 90 & 50 & 23 & 24 & 0.8980 & 0.7091 \\
\hline 24 & 420 & 200 & 24 & 25 & 0.8960 & 0.7011 \\
\hline 25 & 420 & 200 & 6 & 26 & 0.2030 & 0.1034 \\
\hline 26 & 60 & 25 & 26 & 27 & 0.2842 & 0.1447 \\
\hline 27 & 60 & 25 & 27 & 28 & 1.0590 & 0.9337 \\
\hline 28 & 60 & 20 & 28 & 29 & 0.8042 & 0.7006 \\
\hline 29 & 120 & 70 & 29 & 30 & 0.5075 & 0.2585 \\
\hline 30 & 200 & 600 & 30 & 31 & 0.9744 & 0.9630 \\
\hline 31 & 150 & 70 & 31 & 32 & 0.3105 & 0.3619 \\
\hline 32 & 210 & 100 & 32 & 33 & 0.3410 & 0.5302 \\
\hline 33 & 60 & 40 & & & & \\
\cline { 1 - 2 } & & & & & & \\
\hline
\end{tabular}

$$
\text { Cost }=F d L C \times L C
$$

$$
\begin{gathered}
F d L C=\sum_{i=1}^{\text {Tkonstr }}\left(\text { DisLC }_{i} \times(1+d)^{\text {Tkonstr- }-i+0.5}\right) \\
\text { Avail }=\frac{A v}{100} \text { or Avail }=1-\frac{F O}{100}-\frac{s O}{52}
\end{gathered}
$$

with $A v$ is the availability factor (\%). Eff is the thermal efficiency (\%). FO and $S O$ are the force and scheduled outages (\%). Tekonom is the economic life (years). Tkonstr is the development time (years). $L C$ is the investment cost (US $\$ / \mathrm{kW}$ ). $O M$ is the operation and maintenance cost (US $\$ / \mathrm{kWy}$ ). $B B B$ is the fuel cost (US\$/106 kcal). Variable $d$ and $D L C$ are the discount rate $(\%)$ and disbursement $(\%)$. The calculation parameters were obtained from the official publication of the Ministry of Energy and Mineral Resources [15].

\section{SiMULATION SETUP}

\section{A. Test System}

The test system used an IEEE 33 bus radial distribution whose topology and network data are shown in Fig. 2 and Table I. The simulation was carried out using MATLAB. 
TABLE II

LOAD PROFILE OF THE ADAUT VILLAGE

\begin{tabular}{|c|c|c|}
\hline Time & $\boldsymbol{P}(\mathbf{k W})$ & $\boldsymbol{Q}$ (kVar) \\
\hline 01:00 AM & 406.9444 & 252.2015 \\
\hline 02:00 AM & 406.9444 & 252.2015 \\
\hline 03:00 AM & 405.5556 & 251.3408 \\
\hline 04:00 AM & 413.8889 & 256.5053 \\
\hline 05:00 AM & 409.7222 & 253.9230 \\
\hline 06:00 AM & 377.7778 & 234.1256 \\
\hline 07:00 AM & 358.3333 & 222.0751 \\
\hline 08:00 AM & 336.1111 & 208.3030 \\
\hline 09:00 AM & 316.6667 & 196.2524 \\
\hline 10:00 AM & 294.4444 & 182.4803 \\
\hline 11:00 AM & 270.8333 & 167.8474 \\
\hline 12:00 PM & 295.8333 & 183.3410 \\
\hline 01:00 PM & 315.2778 & 195.3916 \\
\hline 02:00 PM & 336.1111 & 208.3030 \\
\hline 03:00 PM & 358.3333 & 222.0751 \\
\hline 04:00 PM & 377.7778 & 234.1256 \\
\hline 05:00 PM & 419.4444 & 259.9483 \\
\hline 06:00 PM & 418.0556 & 259.0876 \\
\hline 07:00 PM & 416.6667 & 258.2268 \\
\hline 08:00 PM & 415.2778 & 257.3660 \\
\hline 09:00 PM & 411.1111 & 254.7838 \\
\hline 10:00 PM & 415.2778 & 257.3660 \\
\hline 11:00 PM & 409.7222 & 253.9230 \\
\hline 12:00 AM & 412.5000 & 255.6445 \\
\hline
\end{tabular}

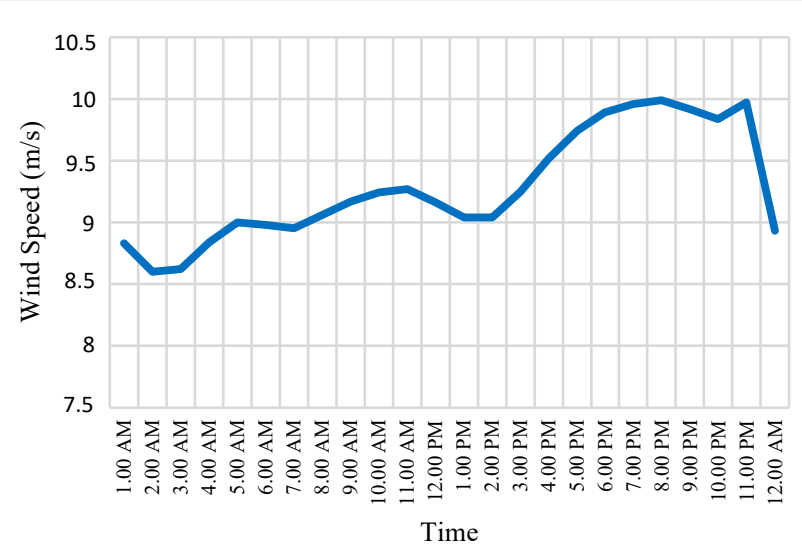

Fig. 3 Wind speed.

\section{B. Case Study}

Adaut Village, Tanimbar Islands Regency, Maluku Province was the case study used in this research. The Adaut Village load profile pattern was applied to each bus of IEEE 33 bus radial distribution that is shown in Table II which peak demand is at 05.00 PM with 419.4444 MW.

Previously, diesels were installed with a capacity of $200 \mathrm{~kW}$, $250 \mathrm{~kW}, 250 \mathrm{~kW}, 250 \mathrm{~kW}, 250 \mathrm{~kW}$ or a total of $1,200 \mathrm{~kW}$. The electricity production can be increased by utilizing wind potential there whose speed is shown in Fig. 3.

\section{RESULT AND DisCUSSION}

This research was carried out with four scenarios, namely with the addition of $1 \mathrm{WT}, 2 \mathrm{WT}, 3 \mathrm{WT}$, and $4 \mathrm{WT}$ scenarios.
TABLE III

THE CAPACITY AND LOCATION OF WT

\begin{tabular}{|c|c|c|}
\hline Scenarios & Size (kW) & Location (Bus) \\
\hline $1 \mathrm{WT}$ & 709.98 & 18 \\
\hline \multirow{2}{*}{$2 \mathrm{WT}$} & 395.99 & 11 \\
\cline { 2 - 3 } & 611.19 & 18 \\
\hline \multirow{3}{*}{$3 \mathrm{WT}$} & 232.47 & 15 \\
\cline { 2 - 3 } & 254.24 & 18 \\
\cline { 2 - 3 } & 620.80 & 30 \\
\hline \multirow{4}{*}{$4 \mathrm{WT}$} & 1.38 & 2 \\
\cline { 2 - 3 } & 422.43 & 15 \\
\cline { 2 - 3 } & 834.33 & 30 \\
\cline { 2 - 3 } & 380.81 & 31 \\
\hline
\end{tabular}

TABLE IV

COMPARISON OF ACTIVE POWER LOSSES

\begin{tabular}{|c|c|c|c|c|c|}
\hline \multirow{2}{*}{ Time } & \multicolumn{5}{|c|}{ Active Power Losses (kW) } \\
\cline { 2 - 6 } & $\begin{array}{c}\text { Without } \\
\boldsymbol{W T}\end{array}$ & $\mathbf{1} \boldsymbol{W T}$ & $\mathbf{2} \boldsymbol{W T}$ & $\mathbf{3} \boldsymbol{W}$ & $\mathbf{4} \boldsymbol{W T}$ \\
\hline 01:00 AM & 194.910 & 109.67 & 89.680 & 72.669 & 41.914 \\
\hline 02:00 AM & 194.910 & 109.67 & 89.680 & 72.669 & 41.914 \\
\hline 03:00 AM & 193.494 & 108.69 & 88.813 & 71.880 & 41.383 \\
\hline 04:00 AM & 202.083 & 114.65 & 94.093 & 76.690 & 44.637 \\
\hline 05:00 AM & 181.749 & 102.53 & 83.109 & 66.731 & 38.956 \\
\hline 06:00 AM & 166.376 & 90.17 & 72.515 & 57.121 & 31.720 \\
\hline 07:00 AM & 148.753 & 78.40 & 62.279 & 47.936 & 26.023 \\
\hline 08:00 AM & 129.949 & 66.15 & 51.738 & 38.571 & 20.568 \\
\hline 09:00 AM & 114.641 & 56.44 & 43.508 & 31.350 & 16.701 \\
\hline 10:00 AM & 98.429 & 46.50 & 35.218 & 24.187 & 13.301 \\
\hline 11:00 AM & 82.671 & 37.24 & 27.686 & 17.827 & 10.857 \\
\hline 12:00 PM & 99.403 & 47.08 & 35.701 & 24.601 & 13.482 \\
\hline 01:00 PM & 113.588 & 55.79 & 42.956 & 30.868 & 16.457 \\
\hline 02:00 PM & 129.949 & 66.15 & 51.738 & 38.571 & 20.568 \\
\hline 03:00 PM & 148.753 & 78.40 & 62.279 & 47.936 & 26.023 \\
\hline 04:00 PM & 166.376 & 90.17 & 72.515 & 57.121 & 31.720 \\
\hline 05:00 PM & 207.927 & 118.72 & 97.715 & 79.996 & 46.899 \\
\hline 06:00 PM & 206.457 & 117.70 & 96.802 & 79.162 & 46.327 \\
\hline 07:00 PM & 204.668 & 116.43 & 95.667 & 78.124 & 45.599 \\
\hline 08:00 PM & 203.535 & 115.66 & 94.991 & 77.509 & 45.196 \\
\hline 09:00 PM & 199.196 & 112.64 & 92.313 & 75.067 & 43.534 \\
\hline 10:00 PM & 203.535 & 115.66 & 94.991 & 77.509 & 45.196 \\
\hline 11:00 PM & 197.762 & 111.65 & 91.430 & 74.263 & 42.989 \\
\hline 12:00 AM & 200.636 & 113.64 & 93.200 & 75.876 & 44.083 \\
\hline Total & $3,989.750$ & $2,179.80$ & $1,760.600$ & $1,394.200$ & 796.050 \\
\hline Round & $4,000.000$ & $2,200.00$ & $1,800.000$ & $1,400.000$ & 800.000 \\
\hline & & & & & \\
\hline
\end{tabular}

NSGA-II obtained the best result in which power losses and voltage deviations were significantly decreased which capacity and location of WT is shown in Table III.

\section{Power Losses}

The power losses in the scenario of adding $1 \mathrm{WT}$ decreased by $45.4 \%$, the scenario of adding 2 WT decreased by $56 \%$, the scenario of adding $3 \mathrm{WT}$ decreased by $65 \%$, and the scenario of adding 4 WT decreased by $80 \%$. Table IV shows the comparison of active power losses in each scenario.

\section{Voltage Deviation}

The effect of voltage deviation on the distribution network in the initial condition scenario, $1 \mathrm{WT}, 2 \mathrm{WT}, 3 \mathrm{WT}$, and $4 \mathrm{WT}$ was observed in 24-hours simulation. Fig. 4 shows the 


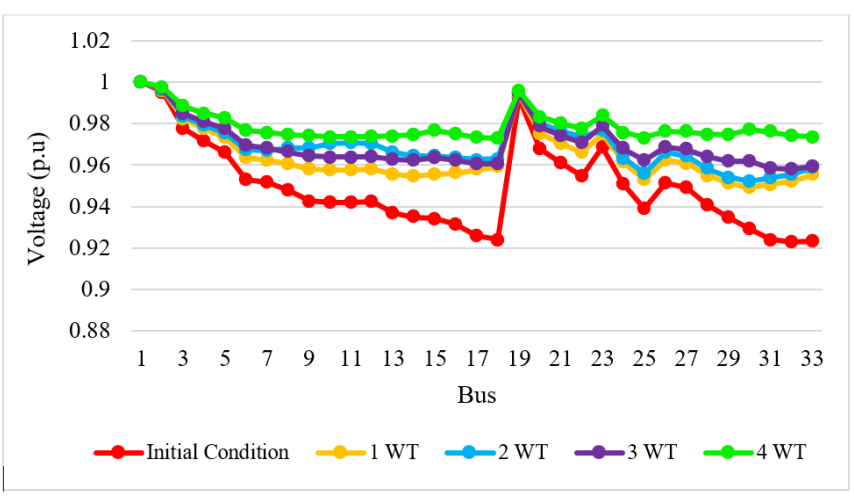

Fig. 4 Voltage profile.

TABLE V

LCOE BASED ON THE SCENARIO

\begin{tabular}{|c|c|c|c|c|}
\hline Scenarios & Generation & $\begin{array}{c}\text { Capacity } \\
(\mathbf{k W})\end{array}$ & $\begin{array}{c}\mathrm{LCOE} \\
\text { (\$cents/kWh) }\end{array}$ & $\begin{array}{c}\text { LCOE } \\
(\mathrm{Rp} / \mathbf{k W h})\end{array}$ \\
\hline \multirow{3}{*}{ I } & Diesel & 1,200 & 43.9539 & $6,181.87$ \\
\hline & $1 \mathrm{WT}$ & 800 & 4.0170 & 564.95 \\
\hline & \multicolumn{2}{|l|}{ Total } & 47.9709 & $6,746.82$ \\
\hline \multirow{4}{*}{ II } & Diesel & 1,200 & 43.9539 & $6,181.87$ \\
\hline & \multirow{2}{*}{$2 \mathrm{WT}$} & 400 & 1.8700 & 263.01 \\
\hline & & 750 & 5.5500 & 780.58 \\
\hline & \multicolumn{2}{|l|}{ Total } & 51.3739 & 7225.46 \\
\hline \multirow{5}{*}{ III } & Diesel & 1,200 & 43.9539 & $6,181.87$ \\
\hline & \multirow{3}{*}{$3 \mathrm{WT}$} & 235 & 2.6900 & 378.33 \\
\hline & & 300 & 1.0380 & 145.99 \\
\hline & & 750 & 5.5500 & 780.58 \\
\hline & \multicolumn{2}{|l|}{ Total } & 53.2319 & $7,486.77$ \\
\hline \multirow{6}{*}{ IV } & Diesel & 1,200 & 43.9539 & $6,181.87$ \\
\hline & \multirow{4}{*}{$4 \mathrm{WT}$} & 2 & 0.0166 & 2.33 \\
\hline & & 400 & 1.8700 & 263.01 \\
\hline & & 450 & 2.1700 & 305.20 \\
\hline & & 1,000 & 2.5650 & 360.74 \\
\hline & \multicolumn{2}{|l|}{ Total } & 50.5755 & $7,113.15$ \\
\hline
\end{tabular}

occurrence of an increase in voltage where in scenario 4 WT get the best voltage profile. The increase in voltage is close to the nominal voltage of $1 \mathrm{pu}$ so as to minimize voltage deviations. At the peak load hours at 05.00 PM, it can be observed that the best voltage improvement is obtained on Bus 32, which is from 0.92399 and increases to 0.9731 . It means that voltage deviation can be minimized to 0.0269 .

\section{E. Economic Aspect}

The cost of generating diesel and WT in the distribution network has been calculated using the LCOE. The location and capacity obtained from the optimization results and LCOE calculations are shown in Table V. The capacity used is rounded up before calculating using LCOE.

\section{CONCLUSION}

The research applied an optimization technique for determining the capacity and location of WT using NSGA-II with an objective function of power losses and voltage deviation. The best results were obtained in scenario IV: 1.38 $\mathrm{kW}$ on Bus 2, $422.43 \mathrm{~kW}$ on Bus 15, $834.33 \mathrm{~kW}$ on Bus 30, and $380.81 \mathrm{~kW}$ on Bus 31 which can reduce power losses by $80 \%$ and minimum deviation voltage was 0.0269 with an LCOE value of $\mathrm{Rp} 7,113.15 / \mathrm{kWh}$.

\section{REFERENCES}

[1] R.C.D. Sarikin, “Analisis Susut Daya dan Energi pada Jaringan Distribusi di PT. PLN (Persero) Rayon Panakkukang," Jurnal Teknologi Elekterika, Vol. 16, No. 1, pp. 43-47, 2019.

[2] S. Sugianto, A. Jaya, and B.A. Ashad, "Analisis Rugi-Rugi Daya Jaringan Distribusi Penyulang POLDA Area Makassar Utara dengan ETAP 12.6," PROtek Jurnal Ilmiah Teknik Elektro, Vol. 7, No. 1, pp. 51-54, 2020.

[3] Y. Prasetyo, A.C. Arifin, and T. Multazam, “Analisis Rekonfigurasi dan Penempatan Kapasitor untuk Meminimalkan Deviasi Tegangan pada Sistem Distribusi," J. Geuthee Inst., Vol. 1, No. 2, pp. 117-126, 2018.

[4] S.K. Injeti and V.K. Thunuguntla, "Optimal Integration of DGs into Radial Distribution Network in the Presence of Plug-in Electric Vehicles to Minimize Daily Active Power Losses and to Improve the Voltage Profile of the System Using Bio-inspired Optimization Algorithms," Protection and Control of Modern Power Systems, Vol. 5, pp. 1-15, 2020.

[5] E.S. Ali, S.M. Abd Elazim, and A.Y. Abdelaziz, "Ant Lion Optimization Algorithm for Optimal Location and Sizing of Renewable Distributed Generations," Renewable Energy, Vol. 101, pp. 1311-1324, 2017.

[6] M. Jesuli, R. Gianto, and M.I. Arsyad, "Pengaruh Pembangkit Tersebar Terhadap Rugi-Rugi Daya Sistem Distribusi Tenaga Listrik," Jurnal Teknik Elektro Universitas Tanjungpura, Vol. 1, pp. 1-8, 2021.

[7] R. Pena, R. Cardenas, J. Clare, and G. Asher, "Wind - Diesel Generation Using Doubly Fed Induction Machines," IEEE Transactions on Energy Conversion, Vol. 23, No. 1, pp. 202-214, 2008.

[8] R.A. Jabr and B.C. Pal, "Ordinal Optimisation Approach for Locating and Sizing of Distributed Generation," IET Generation, Transmission \& Distribution, Vol. 3, No. 8, pp. 713-723, 2009.

[9] G. Aquila, W. Toshiro, and P. Rotella, "Perspectives under Uncertainties and Risk in Wind Farms Investments Based on Omega-LCOE Approach: An Analysis in Sao Paulo State, Brazil," Renewable and Sustainable Energy Reviews, Vol. 141, pp. 1-13, 2021.

[10] B.V. Reddy, "Sizing of DG Units Using Exact Loss Formula to Improve Efficiency of Radial Distribution System," International Journal of Emerging Trends in Electrical and Electronics, Vol. 10, No. 1, pp. 13-17, 2014.

[11] R. Afrianita and H.D. Laksono, "Studi Aliran Daya dengan Metoda Newton Raphson (Aplikasi PT. PLN Sumbar-Riau $150 \mathrm{KV})$," Teknika, Vol. 27, No. 2, pp. 25-33, 2007.

[12] D.S. Donoriyanto, A.S. Anam, and E.W. Pudji, "Application of Genetic Algorithm Method on Machine Maintenance," Journal of Physics: Conference Series, Vol. 953, pp. 1-6, 2017.

[13] K.S. Sambaiah, "A Review on Optimal Allocation and Sizing Techniques for DG in Distribution Systems," International Journal of Renewable Energy Research, Vol. 8, No. 3, pp. 1236-1256, 2018.

[14] A. Jam, M.M. Ardehali, and S.H. Hosseinian, "A Comprehensive Approach for Wind Turbine Generation Allocation with Accurate Analysis of Load Curtailment Using Nested Programming," Energy, Vol. 133, pp. 1063-1078, 2017.

[15] Sunarti, Kajian Penyediaan dan Pemanfaatan Migas, Batubara, EBT dan Listrik, 1st ed., Jakarta, Indonesia: Pusat Data dan Teknologi Informasi Energi dan Sumber Daya Mineral Kementerian Energi dan Sumber Daya Mineral, 2017. 